\title{
Identification of Patients Eligible for IV-to-PO Conversion: A Cost-Minimization Study
}

\author{
Merisa Mok, Angus Kinkade, Anthony Tung, and Aaron M Tejani
}

\section{INTRODUCTION}

$\mathrm{P}$ rograms for converting from intravenous (IV) to oral (PO) formulations have been established by various Canadian health authorities, including the Fraser Health Authority in British Columbia. The clinical and economic benefits achieved through these programs are clear: timely conversion of targeted IV medications to highly bioavailable oral forms can minimize IV line-related infections and administration adverse effects. ${ }^{1,2}$ Increasing the rate of IV-to-PO conversion for antibiotics is also an important aspect of antimicrobial stewardship. ${ }^{3}$ Costs have been reduced through reductions in use of IV medications and equipment (sets and pumps), in the human resources required for drug administration, in length of hospital stay, and in the management of IV complications.-7 An IV-to-PO conversion program is a logical strategy to maintain medication efficacy and minimize financial costs. ${ }^{6,8}$

Although conversion programs are in place and their advantages are known, IV-to-PO conversion rates are suboptimal. ${ }^{4,5,7}$ Possible reasons for delayed or missed conversion may vary; for example, barriers for health care providers may include insufficient clinical information, concerns about therapeutic failure, and the need to complete more urgent tasks., ${ }^{4,7,9,10}$ The criteria for conversion are generally based on the patient's overall clinical status, tolerance of oral intake, and gastrointestinal tract function. ${ }^{1}$ The presence of oral medication intake is an established criterion for IV-to-PO conversion, but there is also emerging research on evaluating dietary orders as a means to identify patients for whom conversion would be appropriate; more specifically, patients who have a functioning gastrointestinal tract and can tolerate an oral diet can receive oral medications. ${ }^{4}$ Using dietary orders to review the eligibility for IV-to-PO stepdown of patients receiving 4 medications (i.e., voriconazole, chlorothiazide, levetiracetam, pantoprazole) and a retrospective budget impact analysis, Lau and others ${ }^{4}$ estimated that $\$ 1166760$ in medication costs could have been saved annually at Johns Hopkins Hospital. Other studies have used computer- ized reminders and reports based on electronic dietary orders to improve conversion rates. ${ }^{11,12}$

The Fraser Health Authority includes 12 acute care sites serving 1.6 million people in communities spanning Burnaby through Hope to Boston Bar. ${ }^{13}$ On a typical day, a total of 2065 patients are admitted to acute care beds across the health authority. The pharmacy departments servicing these acute care sites use IV-to-PO conversions as a performance metric. Over the period November 17 to 30, 2014, a total of 487 conversions by pharmacists were documented at these acute care sites. Currently, there are no formal IV-to-PO conversion programs in the Fraser Health Authority; instead, the clinical pharmacists have access to tools that provide information about appropriate IV-to-PO conversion. Evaluation of dietary orders might improve IV-to-PO conversion efficiency in these clinical settings.

The aims of this study were to determine, on the basis of predefined criteria, the extent to which patients could have had medication orders switched from IV to oral forms, to determine which of these criteria were the most common reasons for eligibility, and to estimate the cost savings associated with these potential conversions.

\section{METHODS}

This cross-sectional study aimed to quantify IV therapy that was eligible for conversion to oral therapy but was not converted. The primary objective was to determine the number of days of IV therapy eligible for IV-to-PO conversion. The secondary objective was to determine the proportion of patients eligible for IV-to-PO conversion out of all patients receiving IV therapy. Because the oral formulations have comparable bioavailability and are expected to have similar therapeutic outcomes, a cost-minimization analysis was used to compare the cost difference between the IV and oral formulations of target drugs.

The medications targeted for this study were ciprofloxacin, fluconazole, linezolid, moxifloxacin, pantoprazole, and ranitidine, and all patients receiving an IV formulation of these 
medications were considered for inclusion. These medications were chosen on the basis of their high bioavailability and the simplicity of IV-to-PO conversion. Consideration was also given to medications with high rate of use or a high cost differential between IV and oral formulations.

IV orders for target medications were identified from the pharmacy information system. A search report was created to identify all orders for IV administration of target medications started between April 1, 2014, and March 31, 2015, at any acute care site in the Fraser Health Authority. Repeat orders for the same patient were removed, leaving only the first IV order for each target drug per patient per admission.

A convenience sample of 200 orders was chosen, based on the following determination that this sample size would achieve a $95 \%$ confidence interval (CI) no wider than $\pm 5 \%$ for the primary outcome. Given a total of 69964 days of IV therapy with the target medications during the study period, 500 days of therapy would be required to achieve a $95 \% \mathrm{CI}$ of $\pm 4.37 \%$. The same usage data showed that the average duration of IV therapy with the target medications was 2.61 days, so 192 orders would be required to achieve 500 days of therapy. The sampling population of orders was re-sorted into a random sequence, and data were collected until 200 orders had been reviewed in a ratio proportional to hospital size. Only orders from the 6 sites with electronic charts were included.

Patients were excluded from the study if they were younger than 18 years of age, if they had received the target medication in IV and oral forms concurrently, if they did not receive targeted IV therapy, or if information in their medical charts was insufficient for the purposes of analysis. Orders for pantoprazole as a continuous infusion for acute upper gastrointestinal bleeding were also excluded, since this therapy would not be eligible for IV-to-PO conversion.

Patients' eligibility for IV-to-PO conversion was determined by comparing data from medical records with prespecified criteria (Box 1). For each patient, the location where IV therapy was started was identified from the search report. Data on the duration of IV therapy and of other nontargeted oral medications ordered were collected from the patient profile. Fraser Health Authority nutrition services documents the current diet order for each patient in the electronic medical record (e.g., NPO status [nothing by mouth], oral diet, parenteral nutrition). ${ }^{14}$ This information was extracted for each order and was used to determine eligibility for oral conversion of medications: specifically, if an oral diet was being given to a patient, then the order for the target medication was considered eligible for oral conversion. It was determined before data collection that none of the targeted drugs would have drug interactions affecting oral medication absorption that could not be managed.

One author (M.M.) extracted data during July and August 2015. The same author then cleaned the data, looking for

\section{Box 1. Eligibility Criteria for Conversion from IV to Oral Medication}

Order meets the following 3 criteria:

- Targeted IV medication administered in non-ICU ward

- Targeted IV medication administered $>48 \mathrm{~h}$

- No drug-drug interactions that would affect absorption of oral medication and that cannot be managed AND

Patient has received any of the following*:

- Dietary order that is not NPO

- Nontargeted oral medications

$\mathrm{ICU}=$ intensive care unit, $\mathrm{IV}=$ intravenous,

$\mathrm{NPO}=$ nothing by mouth .

*With confirmation that dietary order and/or nontargeted oral medication was actually received.

unexpected values, typos, and transcription errors, and then performed descriptive data analysis using Microsoft Excel (Redmond, Washington).

Once eligibility for IV-to-PO conversion was established according to the study criteria, the same author (M.M.) calculated the number of days missed and the number of doses missed for potential oral therapy. In this study, a day was defined as the 24-h period between 2 calendar days (e.g., May 7 to May 8). The dose calculation was based on the assumption that doses were ordered at noon (1200) and stopped by noon (1200) on the calendar day the drug was discontinued. Medication administration records (MARs) were used to confirm whether doses had been taken.

The proportion of eligible patients was calculated as the number of patients with IV therapy eligible for IV-to-PO conversion divided by the total number of included patients.

Medication costs because of delayed or missed IV-to-PO conversion were extrapolated to the entire health authority using Canadian list price information and the following formula:

$\begin{aligned} & \text { Potential savings } \\ & \text { from IV-to-PO } \\ & \text { conversions }\end{aligned} \quad \begin{aligned} & \text { No. of IV doses fiscal year } \\ & \text { missed in study }\end{aligned} \times \begin{aligned} & \text { Proportion of } \\ & \text { oral doses }\end{aligned} \times \begin{aligned} & \text { Cost savings } \\ & \text { per dose }\end{aligned}$

The sum of cost savings for each IV medication was then calculated.

Descriptive statistics were used in this study. Continuous variables are represented as means with $95 \% \mathrm{CIs}$, and categorical variables are expressed as proportions.

This study received an ethics review exemption from the Fraser Health Authority Research Ethics Board because of the retrospective, non-interventional nature of the study design.

\section{RESULTS}

Records for 200 patients were screened, and totals of 144 patients (Table 1) and 335 days of IV therapy (Table 2) were included in the analysis. Of the 6 targeted IV medications, only 4 were ordered for the eligible patients: no patients who were eligible for IV-to-PO conversion received IV fluconazole or linezolid therapy. 
Fifty of the patients $(34.7 \%)$ had at least one order that was eligible for IV-to-PO conversion. Reasons for orders being ineligible for conversion were $48 \mathrm{~h}$ or less of antibiotic therapy, admission to the ICU, or NPO status (Table 3). Eligibility for conversion to oral therapy was based on the presence of an oral diet order for $42(84 \%)$ of the 50 patients and the presence of oral orders for other (nontarget) medications for 8 patients (16\%).

Of the 335 days of IV therapy analyzed, 138 days (95\% CI 132.95-143.05) of oral therapy were either delayed or missed (Table 2); this represented $41.2 \%$ of the days of IV therapy. Among patients eligible for IV-to-PO conversion, the average number of delayed or missed oral therapy days was 2.76 days (95\% CI 2.06-3.46). For the population as a whole (i.e., including in the denominator patients ineligible for IV-to-PO step-down), the average number of delayed or missed days of oral therapy was 0.96 days $(95 \%$ CI $0.55-1.37)$ per patient.

\section{Table 1. Patient Characteristics}

\begin{tabular}{|c|c|c|}
\hline \multirow{2}{*}{$\begin{array}{l}\text { Characteristic } \\
\text { Age (years), median (range) }\end{array}$} & \multicolumn{2}{|c|}{$\begin{array}{c}\text { No. (\%) of Patients* } \\
(n=144)\end{array}$} \\
\hline & 69.5 & $(22-96)$ \\
\hline Sex, male & 76 & $(52.8)$ \\
\hline \multicolumn{3}{|l|}{ Hospital site } \\
\hline Surrey Memorial Hospital & 71 & $(49.3)$ \\
\hline Abbotsford Regional Hospital & 26 & $(18.1)$ \\
\hline Burnaby Hospital & 23 & $(16.0)$ \\
\hline Langley Memorial Hospital & 15 & $(10.4)$ \\
\hline Delta Hospital & 5 & (3.5) \\
\hline Mission Memorial Hospital & 4 & $(2.8)$ \\
\hline $\ln I C U$ & 29 & $(20.1)$ \\
\hline Duration of stay (days), mean (range) & 18 & $(0-164)$ \\
\hline \multicolumn{3}{|l|}{ Indication for IV medication } \\
\hline Peptic ulcer disease/GERD & 49 & $(34.0)$ \\
\hline Respiratory infection & 37 & $(25.7)$ \\
\hline Gastrointestinal infection & 24 & $(16.7)$ \\
\hline Urinary tract infection & 9 & (6.3) \\
\hline Other & 25 & $(17.4)$ \\
\hline
\end{tabular}

On the basis of list prices, a total of $\$ 4015.50$ in medication costs could have been saved for these 50 patients (Table 4). Given the total number of doses that were administered during the fiscal year, an estimated $\$ 788660.07$ of medication costs could have been saved.

\section{DISCUSSION}

In this study, more than $40 \%$ of days of IV therapy were eligible for conversion to oral therapy, and an average of almost 1 day of oral therapy was missed per patient, over the total cohort of hospital inpatients.

We recognize that conversion eligibility cannot be determined by a single criterion and requires clinical judgment; therefore, we designed a conservative approach for fulfilling the study objectives. With this approach, the assumption about when doses were ordered and discontinued was set to account for the potential delay between medication ordering and administration that may occur in practice. MAR information was used to confirm whether medications had been taken, and this process showed discrepancies between actual and calculated days and doses. For example, an MAR might indicate that the patient received 2 targeted IV medication doses from May 7 to 8 , but our calculation for number of days (i.e., $24 \mathrm{~h}$ over 2 calendar days) and doses might indicate that the patient received only one dose. Of the 144 included patients, 94 were deemed ineligible for oral medications according to the study criteria (i.e., were in the ICU, received antibiotics for no more than 48 hours, or had NPO status). These patients might have been

Table 3. Reasons for Ineligibility for IV-to-PO Step-Down

\begin{tabular}{lrr} 
Main Reason & $\begin{array}{c}\text { No. (\%) of Ineligible } \\
\text { Patients }(\boldsymbol{n}=\mathbf{9 4})\end{array}$ \\
\hline Antibiotic use $\leq 48 \mathrm{~h}$ & 48 & $(51.1)$ \\
In ICU & 29 & $(30.9)$ \\
NPO status & 12 & $(12.8)$ \\
Received medication but had 0 days' & 5 & $(5.3)$ \\
supply (based on definition) & & \\
\hline ICU = intensive care unit, IV = intravenous, & & \\
NPO = nothing by mouth. &
\end{tabular}

Table 2. Target Drug Characteristics

\begin{tabular}{|c|c|c|c|c|c|c|c|c|}
\hline \multirow{3}{*}{$\begin{array}{l}\text { IV Antibiotic } \\
\text { Ciprofloxacin }\end{array}$} & \multicolumn{4}{|c|}{$\begin{array}{l}\text { All Included Patients } \\
\qquad(n=144)\end{array}$} & \multicolumn{4}{|c|}{$\begin{array}{l}\text { Patients Eligible } \\
\text { For IV-to-PO Stepdown }(n=50)\end{array}$} \\
\hline & \multicolumn{2}{|c|}{$\begin{array}{l}\text { No. (\%) of } \\
\text { Patients }\end{array}$} & \multirow{2}{*}{$\begin{array}{c}\begin{array}{c}\text { Days of IV } \\
\text { Therapy }\end{array} \\
111\end{array}$} & \multirow{2}{*}{$\begin{array}{l}\text { No. of Doses } \\
204\end{array}$} & \multicolumn{2}{|c|}{$\begin{array}{l}\text { No. of PO Days Missed/ } \\
\text { No. of IV Days } \\
\text { Received (\%)* }\end{array}$} & \multicolumn{2}{|c|}{$\begin{array}{l}\text { No. of PO Doses Missed } \\
\text { No. of IV Doses } \\
\text { Received (\%)* }\end{array}$} \\
\hline & 42 & $(29.2)$ & & & $52 / 80$ & $(65.0)$ & $97 / 145$ & (66.9) \\
\hline Fluconazole & 4 & $(2.8)$ & 2 & 6 & 0 & & 0 & \\
\hline Linezolid & 4 & (2.8) & 7 & 14 & 0 & & 0 & \\
\hline Moxifloxacin & 37 & $(25.7)$ & 75 & 75 & $22 / 44$ & $(50.0)$ & $22 / 44$ & $(50.0)$ \\
\hline Pantoprazole & 40 & $(27.8)$ & 113 & 220 & $57 / 74$ & (77.0) & $105 / 126$ & (83.3) \\
\hline Ranitidine & 17 & $(11.8)$ & 27 & 74 & $7 / 16$ & (43.8) & $20 / 47$ & $(42.6)$ \\
\hline Total & & $\mathrm{VA}$ & 335 days & 593 doses & $138 \mathrm{POd}$ & ays missed & $244 \mathrm{PO}$ do & es missed \\
\hline
\end{tabular}

$\mathrm{IV}=$ intravenous, $\mathrm{NA}=$ not applicable, $\mathrm{PO}=$ oral administration.

* For the particular medication. 
This single copy is for your personal, non-commercial use only.

For permission to reprint multiple copies or to order presentation-ready copies for distribution, contact CJHP at cjhpedit@cshp.ca

Table 4. Potential Cost Savings for IV-to-PO Medication Conversion (Based on Canadian List Prices)

\begin{tabular}{|c|c|c|c|c|c|c|c|c|}
\hline \multirow[b]{2}{*}{ Medication } & \multicolumn{3}{|c|}{ Cost/Dose, \$ } & \multirow[b]{2}{*}{$\begin{array}{c}\text { No. PO Doses } \\
\text { Missed* }^{*}\end{array}$} & \multirow[b]{2}{*}{$\begin{array}{l}\text { Potential } \\
\text { Cost } \\
\text { Saving,\$* }\end{array}$} & \multicolumn{2}{|c|}{ No. of IV Doses } & \multirow[b]{2}{*}{$\begin{array}{l}\text { Potential Cost } \\
\text { Saving/FY, \$十 }\end{array}$} \\
\hline & IV & PO & Saving & & & $\begin{array}{l}\text { During } \\
\text { Study }\end{array}$ & $\begin{array}{c}\text { In Fiscal } \\
\text { Year }\end{array}$ & \\
\hline Ciprofloxacin & $\begin{array}{c}23.91 \\
\text { (400-mg bag) }\end{array}$ & $\begin{array}{c}0.98 \\
(500-m g \text { tab) }\end{array}$ & 22.93 & 97 & 2224.21 & 204 & 28497 & 310702.51 \\
\hline Moxifloxacin & $\begin{array}{c}35.02 \\
\text { (400-mg bag) }\end{array}$ & $\begin{array}{c}5.50 \\
(400-m g \text { tab) }\end{array}$ & 29.52 & 22 & 649.44 & 75 & 13752 & 119081.32 \\
\hline Pantoprazole (vial) & $\begin{array}{c}10.96 \\
\text { (40-mg vial) }\end{array}$ & $\begin{array}{c}0.51 \\
(40-m g \text { tab) }\end{array}$ & 10.45 & 105 & 1097.25 & 220 & 69165 & 344960.44 \\
\hline Ranitidine & $\begin{array}{c}2.66 \\
\text { (50-mg vial) }\end{array}$ & $\begin{array}{c}0.43 \\
\text { (75-mg tab) }\end{array}$ & 2.23 & 20 & 44.60 & 74 & 23089 & 13915.80 \\
\hline Total & NA & NA & NA & NA & 4015.50 & $\mathrm{NA}$ & NA & 788660.07 \\
\hline
\end{tabular}

eligible for IV-to-PO conversion if we had used a more individualized assessment, but we classified them as ineligible to reduce the potential for hindsight bias.

In the calculation of potential cost savings in this study, only medication costs were considered; costs for IV administration and equipment, costs related to clinical skills in assessing and monitoring patients, and costs associated with the hospital stay were not included. Cost savings could be expected to increase if these additional costs were included. In addition, only 4 of the 6 targeted IV medications were being taken by eligible patients. Potential cost savings might have been higher if fluconazole and linezolid orders had been identified. Although pantoprazole (in IV vial and bag formulations) had the largest number of missed or delayed oral days and doses, its cost differential (\$10.45) was substantially lower than the cost differentials for ciprofloxacin and moxifloxacin (\$22.93 and $\$ 29.52$, respectively). In contrast, the medications studied in the Johns Hopkins Hospital retrospective budget impact analysis (voriconazole, chlorothiazide, levetiracetam, pantoprazole) ${ }^{4}$ had cost differentials on the order of hundreds of dollars, based on 2011 Red Book average wholesale prices. ${ }^{15}$ Medication cost savings are expected to vary among different hospital authorities, depending on the medications studied, their specific costs, and contract pricing differences.

\section{Limitations}

The lack of interactions between patients and clinicians, the possibility of insufficient documentation, and the potential for hindsight bias are limitations of a retrospective chart review. We attempted to overcome these limitations with a conservative study approach. A conservative approach may underestimate values, but the results obtained here can be viewed as being close to the minimum benefit expected from using oral intake status to determine eligibility for oral administration of medications. For patients who do not meet inclusion or eligibility criteria for IV-to-PO conversion, clinicians can use professional judgment to determine whether they can receive medications by the oral route.

Although data on patients' locations within the hospital were collected, we did not record the service with which each patient was associated or the ordering physician's specialty. Such information might have enhanced our interpretation of the results, but the randomized nature of participant selection would be adequate in minimizing selection bias.

Because of the unexpectedly large number of patients who were excluded from the study (56 of 200), the margin of error increased slightly, from $4.37 \%$ to $5.05 \%$. If the study had had a larger sample size, the results would have been more precise; however, with the current level of precision, we feel that the results are meaningful, i.e., roughly $30 \%$ to $40 \%$ of patients had a medication order eligible for oral conversion, which represents an important missed opportunity. Only 6 medications were targeted in this study, and the findings might be different if a greater number of highly bioavailable medications were studied. Specifically, for determination of medication cost savings, fluconazole and linezolid had the greatest cost difference among all 6 targeted medications, but there were no orders for these 2 medications during the study period, and therefore they were not included in cost calculations.

Since the eligibility criteria for IV-to-PO conversion depended in part on orders for nontarget oral medications, these results assume that those orders were appropriate for patients with adequate oral intake and absorption, which may not have been the case. In addition, there may have been situations in which another medication was ordered for oral administration but for which oral absorption was not necessary (e.g., oral vancomycin for treatment of Clostridium difficile diarrhea). It is unlikely that such a situation substantially affected the results, given that only $16 \%$ of patients were deemed eligible for IV-to-PO conversion on the basis of other medications and most of these patients were receiving more than one nontarget oral medication. 


\section{Implications}

The findings from this study demonstrate the potential for using dietary orders to improve identification of patients for IV-to-PO conversion. Assessment for conversion eligibility can be a time-consuming process and may be more efficient with reminder systems and screening tools such as dietary orders. Within the Fraser Health Authority, suitable candidates for IV-to-PO conversion are typically identified through direct patient interview. Given the high patient volumes in this health authority, interviews are not always feasible, especially for off-service patients; a tool to screen out obviously ineligible patients would help to minimize the time spent assessing patients for conversion eligibility. In several studies, conversion rates and cost savings have improved with the use of reminders, in computerized provider order entry systems, about patients receiving IV medications and oral intake. ${ }^{11,12,16}$ In a number of health care systems where such systems have not been established, clinicians may benefit from reminders about oral intake status and potential IV-to-PO conversion in daily self-populating monitoring sheets.

The method used to calculate medication cost savings in this study was simple to apply and can be used to monitor cost saving trends related to IV-to-PO conversion programs. The information used for this analysis was readily available to all clinicians and is thus feasible to include in clinical reports already in use by clinical pharmacists. Within the Fraser Health Authority, a screening report to identify potential patients for IV-to-PO conversion will be explored, which could allow clinical technicians or pharmacy students to easily identify potential candidates. At sites where computerized physician order entry is available, dietary order status can be used to prompt clinicians to consider IV-to-PO step-down. There is an opportunity to analyze rates of IV-to-PO conversion and benefits for other highly bioavailable medications in future studies.

\section{CONCLUSION}

A substantial proportion of patients who were receiving target IV medications were eligible for conversion to oral therapy. Using information related to oral intake (i.e., dietary orders and/or orders for nontargeted oral medications) can support identification of patients eligible for IV-to-PO conversion, thereby reducing medication costs. In this study, at least $41.2 \%$ of oral therapy days were delayed or missed, and $\$ 788660$ in additional medication cost savings could have been saved per year.

\section{References}

1. Kuper K. Intravenous to oral therapy conversion. In: Competence tools for health-system pharmacies. 4th ed. Bethesda (MD): American Society of Health System Pharmacists; 2008. pp. 347-60.

2. Nadeau MC, Kuti EL. Clinical and economic impact of intravenous to oral conversion therapy programs. Conn Med. 2011;75(1):25-9.

3. Sallach-Ruma R, Nieman J, Sankaranarayanan J, Reardon T. Correlates and economic and clinical outcomes of an adult IV to PO antimicrobial conversion program at an academic medical center in midwest United States. J Pharm Pract. 2015;28(3):238-48.
4. Lau BD, Pinto BL, Thiemann DR, Lehmann CU. Budget impact analysis of conversion from intravenous to oral medication when clinically eligible for oral intake. Clin Ther. 2011;33(11):1792-6.

5. Ho BP, Lau TTY, Balen RM, Naumann TL, Jewesson PJ. The impact of a pharmacist-managed dosage form conversion service on ciprofloxacin usage at a major Canadian teaching hospital: a pre- and post-intervention study. BMC Health Serv Res. 2005;5:1-8.

6. Kuti JL, Le TN, Nightingale CH, Nicolau DP, Quintiliani R. Pharmacoeconomics of a pharmacist-managed program for automatically converting levofloxacin route from i.v. to oral. Am J Health Syst Pharm. 2002;59(22):2209-15.

7. Rasoda A, Tejani A, Virani A, Lakhani A. Evaluation of IV to PO step down of fluoroquinolone antibiotics by pharmacists in the Fraser Health Authority [poster]. Canadian Society of Hospital Pharmacists, BC Branch Residency Presentation Night; 2011 May 19; Vancouver (BC).

8. National health expenditure trends, 1975-2014. Ottawa (ON): Canadian Institute for Health Information; 2014.

9. Wong-Beringer A, Nguyen $\mathrm{KH}$, Razeghi J. Implementing a program for switching from i.v. to oral antimicrobial therapy. Am J Health Syst Pharm. 2001;58(12):1146-9.

10. Béique L, Zvonar R. Addressing concerns about changing the route of antimicrobial administration from intravenous to oral in adult inpatients. Can J Hosp Pharm. 2015;68(4):318-26.

11. Teich JM, Petronzio AM, Gerner JR, Seger DL, Shek C, Fanikos J. An information system to promote intravenous-to-oral medication conversion. Proc AMIA Symp. 1999:415-9.

12. Glemaud I. Use of a physician order entry system to identify opportunities for intravenous to oral levofloxacin conversion. Am J Health Syst Pharm. 2000;57 Suppl 3:S14-6.

13. About Fraser Health [website]. New Westminster (BC): Fraser Health Authority; 2016 [cited 2016 Jul 6]. Available from: www.fraserhealth.ca/ about-us/about-fraser-health/

14. Fraser Health nutrition standards. Surrey (BC): Fraser Health Authority, Food and Nutrition Service Department; 2013.

15. Red book: pharmacy's fundamental reference. 115th ed. New York (NY): Thomson Reuters; 2011.

16. Fischer M, Solomon D, Teich J, Avorn J. Conversion from intravenous to oral medications: assessment of a computerized intervention for hospitalized patients. Arch Intern Med. 2003;163(21):2585-9.

Merisa Mok, BSc(Pharm), was, at the time of writing, a student in the Faculty of Pharmaceutical Sciences, University of British Columbia, Vancouver, British Columbia. She is now a resident with the Lower Mainland Pharmacy Services Pharmacy Practice Residency Program, Vancouver, British Columbia.

Angus Kinkade, BSC(Pharm), ACPR, PharmD, MSC, BCPS, is with Lower Mainland Pharmacy Services, Vancouver, British Columbia.

Anthony Tung, BSC(Pharm), ACPR, BCPS, MBA, is with Lower Mainland Pharmacy Services, Vancouver, British Columbia.

Aaron M Tejani, BSc(Pharm), PharmD, ACPR, is with Lower Mainland Pharmacy Services, Vancouver, British Columbia

Competing interests: For work unrelated to the study reported here, Aaron Tejani has received grants from the College of Pharmacists of British Columbia and speaker's honoraria from REACH primary care clinic in Vancouver; the Community and Rural Internal Medicine Society (British Columbia); BC Naturopathic Physicians; Vancouver Island Health Authority Pharmacy Services; University of British Columbia Faculty of Medicine and psychiatry residency program; the Rural Emergency Medicine Continuum of Care BC conference; education days for health care professionals in Yellowknife, Yukon, and Kelowna; and the Therapeutics Initiative (UBC). No other competing interests were declared.

\section{Address correspondence to:}

\section{Dr Angus Kinkade}

Lower Mainland Pharmacy Services

Vancouver General Hospital Heather Pavilion, Level D

2733 Heather Street

Vancouver BC V5Z 1M9

e-mail: angus.kinkade@fraserhealth.ca

Funding: None received. 